\title{
Strong Convergence Theorems for a Generalized Equilibrium Problem with a Relaxed Monotone Mapping and a Countable Family of Nonexpansive Mappings in a Hilbert Space
}

\author{
Shenghua Wang, ${ }^{1}$ Giuseppe Marino, ${ }^{2}$ and Fuhai Wang1 \\ ${ }^{1}$ School of Applied Mathematics and Physics, North China Electric Power University, \\ Baoding 071003, China \\ ${ }^{2}$ Dipartimento di Matematica, Universitá della Calabria, 87036 Arcavacata di Rende, Italy \\ Correspondence should be addressed to Shenghua Wang, sheng-huawang@hotmail.com
}

Received 15 March 2010; Accepted 20 June 2010

Academic Editor: Naujing Jing Huang

Copyright (C) 2010 Shenghua Wang et al. This is an open access article distributed under the Creative Commons Attribution License, which permits unrestricted use, distribution, and reproduction in any medium, provided the original work is properly cited.

\begin{abstract}
We introduce a new iterative method for finding a common element of the set of solutions of a generalized equilibrium problem with a relaxed monotone mapping and the set of common fixed points of a countable family of nonexpansive mappings in a Hilbert space and then prove that the sequence converges strongly to a common element of the two sets. Using this result, we prove several new strong convergence theorems in fixed point problems, variational inequalities, and equilibrium problems.
\end{abstract}

\section{Introduction}

Throughout this paper, let $\mathbb{R}$ denote the set of all real numbers, let $\mathbb{N}$ denote the set of all positive integer numbers, let $H$ be a real Hilbert space, and let $C$ be a nonempty closed convex subset of $H$. Let $S: C \rightarrow C$ be a mapping. We call $S$ nonexpansive if

$$
\|S x-S y\| \leq\|x-y\|, \quad \forall x, y \in C
$$

The set of fixed points of $S$ is denoted by $\operatorname{Fix}(S)$. We know that the set Fix $(S)$ is closed and convex. Let $\Phi: C \times C \rightarrow \mathbb{R}$ be a bifunction. The equilibrium problem for $\Phi$ is to find $z \in C$ such that

$$
\Phi(z, y) \geq 0, \quad \forall y \in C
$$


The set of all solutions of the equilibrium problem is denoted by $\operatorname{EP}(\Phi)$, that is,

$$
\mathrm{EP}(\Phi)=\{z \in C: \Phi(z, y) \geq 0, \forall y \in C\}
$$

Some iterative methods have been proposed to find an element of $\operatorname{EP}(\Phi) \cap \operatorname{Fix}(S)$; see $[1,2]$. A mapping $A: C \rightarrow H$ is called inverse-strongly monotone if there exists $\lambda>0$ such that

$$
\langle x-y, A x-A y\rangle \geq \lambda\|A x-A y\|^{2}, \quad \forall x, y \in C .
$$

Such a mapping $A$ is also called $\lambda$-inverse-strongly monotone. It is known that each nonexpansive mapping is $1 / 2$-inverse-strongly monotone and each $\kappa$-strictly pseudocontraction is $(1-\kappa) / 2$-inverse-strongly monotone; see $[3,4]$. If there exists $u \in C$ such that

$$
\langle v-u, A u\rangle \geq 0, \quad \forall v \in C,
$$

then $u$ is called a solution of the variational inequality. The set of all solutions of the variational inequality is denoted by $\mathrm{VI}(C, A)$. It is known that $\mathrm{VI}(C, A)$ is closed and convex. Recently Takahashi and Toyoda [5] introduced an iterative method for finding an element of $\operatorname{Fix}(S) \cap \operatorname{VI}(C, A)$; see also [6]. On the other hand, Plubtieng and Punpaeng [7] introduced an iterative method for finding an element of $\operatorname{Fix}(S) \cap \operatorname{EP}(\Phi) \cap \mathrm{VI}(C, A)$; see also [8].

Consider a general equilibrium problem:

$$
\text { Find } z \in C \text { such that } \Phi(z, y)+\langle A z, y-z\rangle \geq 0, \quad \forall y \in C \text {. }
$$

The set of all solutions of the equilibrium problem is denoted by EP, that is,

$$
\mathrm{EP}=\{z \in C: \Phi(z, y)+\langle A z, y-z\rangle \geq 0, \forall y \in C\}
$$

In the case of $A \equiv 0, \mathrm{EP}$ coincides with $\mathrm{EP}(\Phi)$. In the case $\Phi \equiv 0$, EP coincides with $\operatorname{VI}(C, A)$. Recently, S. Takahashi and W. Takahashi [9] introduced an iterative method to find an element of $\operatorname{EP} \cap \operatorname{Fix}(S)$. More precisely, they introduced the following iterative scheme: $u \in C, x_{1} \in C$, and

$$
\begin{gathered}
\Phi\left(z_{n}, y\right)+\left\langle A x_{n}, y-z_{n}\right\rangle+\lambda_{n}\left\langle y-z_{n}, z_{n}-x_{n}\right\rangle \geq 0, \quad \forall y \in C, \\
x_{n+1}=\beta_{n} x_{n}+\left(1-\beta_{n}\right) S\left[\alpha_{n} u+\left(1-\alpha_{n}\right) z_{n}\right], \quad n \in \mathbb{N},
\end{gathered}
$$

where $\left\{\alpha_{n}\right\} \subset[0,1],\left\{\beta_{n}\right\} \subset[0,1]$, and $\left\{\lambda_{n}\right\} \subset[0,2 \lambda]$ are three control sequences. They proved that $\left\{x_{n}\right\}$ converges strongly to $z=P_{\operatorname{Fix}(S) \cap E P} u$.

A mapping $T: C \rightarrow H$ is said to be relaxed $\eta-\alpha$ monotone if there exist a mapping $\eta: C \times C \rightarrow H$ and a function $\alpha: H \rightarrow \mathbb{R}$ positively homogeneous of degree $p$, that is, $\alpha(t z)=t^{p} \alpha(z)$ for all $t>0$ and $z \in H$ such that

$$
\langle T x-T y, \eta(x, y)\rangle \geq \alpha(x-y), \quad \forall x, y \in C,
$$


where $p>1$ is a constant; see [10]. In the case of $\eta(x, y)=x-y$ for all $x, y \in C, T$ is said to be relaxed $\alpha$-monotone. In the case of $\eta(x, y)=x-y$ for all $x, y \in C$ and $\alpha(z)=k\|z\|^{p}$, where $p>1$ and $k>0, T$ is said to be $p$-monotone; see [11-13]. In fact, in this case, if $p=2$, then $T$ is a $k$-strongly monotone mapping. Moreover, every monotone mapping is relaxed $\eta-\alpha$ monotone with $\eta(x, y)=x-y$ for all $x, y \in C$ and $\alpha \equiv 0$. mapping:

In this paper, we consider a new general equilibrium problem with a relaxed monotone

$$
\text { Find } z \in C \text { such that } \Phi(z, y)+\langle T z, \eta(y, z)\rangle+\langle A z, y-z\rangle \geq 0, \quad \forall y \in C .
$$

The set of all solutions of the equilibrium problem is denoted by $\operatorname{GEP}(\Phi, T)$, that is,

$$
\operatorname{GEP}(\Phi, T)=\{z \in C: \Phi(z, y)+\langle T z, \eta(y, z)\rangle+\langle A z, y-z\rangle \geq 0, \forall y \in C\}
$$

In the case of $A \equiv 0,(1.10)$ is deduced to

$$
\text { Find } z \in C \text { such that } \Phi(z, y)+\langle T z, \eta(y, z)\rangle \geq 0, \quad \forall y \in C
$$

The set of all solutions of (1.12) is denoted by $\operatorname{EP}(\Phi, T)$, that is,

$$
\mathrm{EP}(\Phi, T)=\{z \in C: \Phi(z, y)+\langle T z, \eta(y, z)\rangle \geq 0, \forall y \in C\}
$$

In the case of $T \equiv 0, \operatorname{GEP}(\Phi, T)$ coincides with EP. In the case of $T \equiv 0$ and $A \equiv 0, \operatorname{GEP}(\Phi, T)$ coincides with $\mathrm{EP}(\Phi)$.

In this paper, we introduce a new iterative scheme for finding a common element of the set of solutions of a general equilibrium problem with a relaxed monotone mapping and the set of common fixed points of a countable family of nonexpansive mappings and then obtain a strong convergence theorem. More precisely, we introduce the following iterative scheme:

$$
\begin{gathered}
x_{1} \in C \text { chosen arbitrarily, } \\
\Phi\left(u_{n}, y\right)+\left\langle T u_{n}, \eta\left(y, u_{n}\right)\right\rangle+\left\langle A x_{n}, y-u_{n}\right\rangle+\frac{1}{\lambda_{n}}\left\langle y-u_{n}, u_{n}-x_{n}\right\rangle \geq 0, \quad \forall y \in C, \\
y_{n}=\alpha_{n} x_{n}+\sum_{i=1}^{n}\left(\alpha_{i-1}-\alpha_{i}\right) \beta_{n} S_{i} x_{n}+\left(1-\alpha_{n}\right)\left(1-\beta_{n}\right) u_{n}, \\
C_{n}=\left\{z \in C:\left\|y_{n}-z\right\| \leq\left\|x_{n}-z\right\|\right\}, \\
D_{n}=\bigcap_{j=1}^{n} C_{j}, \\
x_{n+1}=P_{D_{n}} x_{1}, \quad n \geq 1,
\end{gathered}
$$

where $T: C \rightarrow H$ is a relaxed $\eta-\alpha$ monotone mapping, $A: C \rightarrow H$ is a $\lambda$-inverse-strongly monotone mapping, and $\left\{S_{n}\right\}_{n=1}^{\infty}: C \rightarrow C$ is a countable family of nonexpansive mappings 
such that $F=\bigcap_{n=1}^{\infty} \operatorname{Fix}\left(S_{n}\right) \cap \operatorname{GEP}(\Phi, T) \neq \emptyset, \alpha_{0}=1$, and $\left\{\alpha_{n}\right\}_{n=1}^{\infty},\left\{\beta_{n}\right\}_{n=1}^{\infty}$, and $\left\{\lambda_{n}\right\}_{n=1}^{\infty}$ are three control sequences. We prove that $\left\{x_{n}\right\}$ defined by (1.14) converges strongly to $x^{*}=P_{F} x_{1}$. Using the main result in this paper, we also prove several new strong convergence theorems for finding the elements of $\operatorname{Fix}(S) \cap \mathrm{EP}, \operatorname{Fix}(S) \cap \mathrm{EP}(\Phi), \operatorname{Fix}(S) \cap \mathrm{EP}(\Phi, T)$, and $\operatorname{Fix}(S) \cap \mathrm{VI}(C, A)$, respectively, where $S: C \rightarrow C$ is a nonexpansive mapping.

\section{Preliminaries}

Let $A: C \rightarrow H$ be a $\lambda$-inverse-strongly monotone mapping and let $I$ denote the identity mapping of $H$. For all $x, y \in C$ and $k>0$, one has [6]

$$
\|(I-k A) x-(I-k A) y\|^{2} \leq\|x-y\|^{2}+k(k-2 \lambda)\|A x-A y\|^{2} .
$$

Hence, if $k \in(0,2 \lambda]$, then $I-k A$ is a nonexpansive mapping of $C$ into $H$.

For each point $x \in H$, there exists a unique nearest point of $C$, denoted by $P_{C} x$, such that $\left\|x-P_{C} x\right\| \leq\|x-y\|$ for all $y \in C$. Such a $P_{C}$ is called the metric projection from $H$ onto $C$. The well-known Browder's characterization of $P_{C}$ ensures that $P_{C}$ is a firmly nonexpansive mapping from $H$ onto $C$, that is,

$$
\left\|P_{C} x-P_{C} y\right\|^{2} \leq\left\langle P_{C} x-P_{C} y, x-y\right\rangle, \quad x, y \in H .
$$

Further, we know that for any $x \in H$ and $z \in C, z=P_{C} x$ if and only if

$$
\langle x-z, z-y\rangle \geq 0, \quad \forall y \in C .
$$

Let $S$ be a nonexpansive mapping of $C$ into itself such that $\operatorname{Fix}(S) \neq \emptyset$. Then we have

$$
\widehat{x} \in \operatorname{Fix}(S) \Longleftrightarrow\|S x-x\|^{2} \leq 2\langle x-S x, x-\widehat{x}\rangle, \quad \forall x \in C,
$$

which is obtained directly from the following:

$$
\begin{aligned}
\|x-\widehat{x}\|^{2} & \geq\|S x-S \widehat{x}\|^{2}=\|S x-\widehat{x}\|^{2}=\|S x-x+(x-\widehat{x})\|^{2} \\
& =\|S x-x\|^{2}+\|x-\widehat{x}\|^{2}+2\langle S x-x, x-\widehat{x}\rangle .
\end{aligned}
$$

This inequality is a very useful characterization of $\operatorname{Fix}(S)$. Observe what is more that it immediately yields that $\operatorname{Fix}(S)$ is a convex closed set.

Let $\Phi$ be a bifunction of $C \times C$ into $\mathbb{R}$ satisfying the following conditions:

(A1) $\Phi(x, x)=0$ for all $x \in C$;

(A2) $\Phi$ is monotone, that is, $\Phi(x, y)+\Phi(y, x) \leq 0$ for all $x, y \in C$;

(A3) for each $x, y, z \in C, \lim _{t \downarrow 0} \Phi(t z+(1-t) x, y) \leq \Phi(x, y)$;

(A4) for each $x \in C, y \mapsto \Phi(x, y)$ is convex and lower semicontinuous. 
Definition 2.1 (see [10]). Let $E$ be a Banach space with the dual space $E^{*}$ and let $K$ be a nonempty subset of $E$. Let $T: K \rightarrow E^{*}$ and $\eta: K \times K \rightarrow E$ be two mappings. The mapping $T: K \rightarrow E^{*}$ is said to be $\eta$-hemicontinuous if, for any fixed $x, y \in K$, the function $f:[0,1] \rightarrow(-\infty, \infty)$ defined by $f(t)=\langle T((1-t) x+t y), \eta(x, y)\rangle$ is continuous at $0^{+}$.

Lemma 2.2. Let $H$ be a Hilbert space and let $C$ be a nonempty closed convex subset of $H$. Let $T$ : $C \rightarrow H$ be an $\eta$-hemicontinuous and relaxed $\eta$ - $\alpha$ monotone mapping. Let $\Phi$ be a bifunction from $C \times C$ to $\mathbb{R}$ satisfying (A1) and (A4). Let $r>0$ and $z \in C$. Assume that

(i) $\eta(x, x)=0$ for all $x \in C$;

(ii) for any fixed $u, v \in C$, the mapping $x \mapsto\langle T v, \eta(x, u)\rangle$ is convex.

Then the following problems (2.6) and (2.7) are equivalent:

Find $x \in C$ such that $\Phi(x, y)+\langle T x, \eta(y, x)\rangle+\frac{1}{r}\langle y-x, x-z\rangle \geq 0, \quad \forall y \in C$;

Find $x \in C$ such that $\Phi(x, y)+\langle T y, \eta(y, x)\rangle+\frac{1}{r}\langle y-x, x-z\rangle \geq \alpha(y-x), \quad \forall y \in C$.

Proof. Let $x \in C$ be a solution of the problem (2.6). Since $T$ is relaxed $\eta-\alpha$ monotone, we have

$$
\begin{aligned}
& \Phi(x, y)+\langle T y, \eta(y, x)\rangle+\frac{1}{r}\langle y-x, x-z\rangle \\
& \geq \Phi(x, y)+\alpha(y-x)+\frac{1}{r}\langle y-x, x-z\rangle+\langle T x, \eta(y, x)\rangle \\
& \geq \alpha(y-x), \quad \forall y \in C .
\end{aligned}
$$

Thus $x \in C$ is a solution of the problem (2.7).

Conversely, let $x \in C$ be a solution of the problem (2.7). Letting

$$
y_{t}=(1-t) x+t y, \quad \forall t \in(0,1)
$$

then $y_{t} \in C$. Since $x \in C$ is a solution of the problem (2.7), it follows that

$$
\Phi\left(x, y_{t}\right)+\left\langle T y_{t}, \eta\left(y_{t}, x\right)\right\rangle+\frac{1}{r}\left\langle y_{t}-x, x-z\right\rangle \geq \alpha\left(y_{t}-x\right)=t^{p} \alpha(y-x) .
$$

The conditions (i), (ii), (A1), and (A4) imply that

$$
\begin{aligned}
\left\langle T y_{t}, \eta\left(y_{t}, x\right)\right\rangle & \leq(1-t)\left\langle T y_{t}, \eta(x, x)\right\rangle+t\left\langle T y_{t}, \eta(y, x)\right\rangle \\
& =t\langle T(x+t(y-x)), \eta(y, x)\rangle, \\
\Phi\left(x, y_{t}\right) & \leq(1-t) \Phi(x, x)+t \Phi(x, y)=t \Phi(x, y) .
\end{aligned}
$$


It follows from (2.10)-(2.11) that

$$
\Phi(x, y)+\langle T(x+t(y-x)), \eta(y, x)\rangle+\frac{1}{r}\langle y-x, x-z\rangle \geq t^{p-1} \alpha(y-x), \quad \forall y \in C .
$$

Since $T$ is $\eta$-hemicontinuous and $p>1$, letting $t \rightarrow 0$ in (2.12), we get

$$
\Phi(x, y)+\langle T x, \eta(y, x)\rangle+\frac{1}{r}\langle y-x, x-z\rangle \geq 0
$$

for all $y \in C$. Therefore, $x \in C$ is also a solution of the problem (2.6). This completes the proof.

Definition 2.3 (see [14]). Let $E$ be a Banach space with the dual space $E^{*}$ and let $K$ be a nonempty subset of $E$. A mapping $F: K \rightarrow 2^{E}$ is called a KKM mapping if, for any $\left\{x_{1}, \ldots, x_{n}\right\} \subset K, \overline{\mathrm{cO}}\left\{x_{1}, \ldots, x_{n}\right\} \subset \bigcup_{i=1}^{n} F\left(x_{i}\right)$, where $2^{E}$ denotes the family of all the nonempty subsets of $E$.

Lemma 2.4 (see [14]). Let $M$ be a nonempty subset of a Hausdorff topological vector space $X$ and let $F: M \rightarrow 2^{X}$ be a KKM mapping. If $F(x)$ is closed in $X$ for all $x \in X$ in $K$ and compact for some $x \in K$, then $\bigcap_{x \in M} F(x) \neq \emptyset$.

Next we use the concept of KKM mapping to prove two basic lemmas for our main result. The idea of the proof of the next lemma is contained in the paper of Fang and Huang [10].

Lemma 2.5. Let $H$ be a real Hilbert space and $C$ be a nonempty bounded closed convex subset of $H$. Let $T: C \rightarrow H$ be an $\eta$-hemicontinuous and relaxed $\eta-\alpha$ monotone mapping, and let $\Phi$ be a bifunction from $C \times C$ to $\mathbb{R}$ satisfying (A1) and (A4). Let $r>0$. Assume that

(i) $\eta(x, y)+\eta(y, x)=0$ for all $x, y \in C$;

(ii) for any fixed $u, v \in C$, the mapping $x \mapsto\langle T v, \eta(x, u)\rangle$ is convex and lower semicontinuous;

(iii) $\alpha: H \rightarrow \mathbb{R}$ is weakly lower semicontinuous; that is, for any net $\left\{x_{\beta}\right\}, x_{\beta}$ converges to $x$ in $\sigma(H, H)$ which implies that $\alpha(x) \leq \lim \inf \alpha\left(x_{\beta}\right)$.

Then problem (2.6) is solvable.

Proof. Let $z \in C$. Define two set-valued mappings $F_{z}, G_{z}: C \rightarrow 2^{H}$ as follows:

$$
\begin{gathered}
F_{z}(y)=\left\{x \in C: \Phi(x, y)+\langle T x, \eta(y, x)\rangle+\frac{1}{r}\langle y-x, x-z\rangle \geq 0\right\}, \quad \forall y \in C, \\
G_{z}(y)=\left\{x \in C: \Phi(x, y)+\langle T y, \eta(y, x)\rangle+\frac{1}{r}\langle y-x, x-z\rangle \geq \alpha(y-x)\right\}, \quad \forall y \in C .
\end{gathered}
$$


We claim that $F_{z}$ is a KKM mapping. If $F_{z}$ is not a KKM mapping, then there exist $\left\{y_{1}, \ldots, y_{n}\right\} \subset C$ and $t_{i}>0, i=1, \ldots, n$, such that

$$
\sum_{i=1}^{n} t_{i}=1, \quad y=\sum_{i=1}^{n} t_{i} y_{i} \notin \bigcup_{i=1}^{n} F_{z}\left(y_{i}\right)
$$

By the definition of $F$, we have

$$
\Phi\left(y, y_{i}\right)+\left\langle T y, \eta\left(y_{i}, y\right)\right\rangle+\frac{1}{r}\left\langle y_{i}-y, y-z\right\rangle<0, \quad \forall i=1, \ldots, n
$$

It follows from (A1), (A4), and (ii) that

$$
\begin{aligned}
0 & =\Phi(y, y) \\
& =\Phi\left(y, \sum_{i=1}^{n} t_{i} y_{i}\right)+\left\langle T y, \eta\left(\sum_{i=1}^{n} t_{i} y_{i}, y\right)\right\rangle \\
& \leq \sum_{i=1}^{n} t_{i} \Phi\left(y, y_{i}\right)+\sum_{i=1}^{n} t_{i}\left\langle T y, \eta\left(y_{i}, y\right)\right\rangle \\
& <\sum_{i=1}^{n} t_{i} \frac{1}{r}\left\langle y-y_{i}, y-z\right\rangle \\
& =0
\end{aligned}
$$

which is a contradiction. This implies that $F_{z}$ is a KKM mapping.

Now, we prove that

$$
F_{z}(y) \subset G_{z}(y), \quad \forall y \in C
$$

For any given $y \in C$, taking $x \in F_{z}(y)$, then

$$
\Phi(x, y)+\langle T x, \eta(y, x)\rangle+\frac{1}{r}\langle y-x, x-z\rangle \geq 0
$$

Since $T$ is relaxed $\eta-\alpha$ monotone, we have

$$
\begin{aligned}
& \Phi(x, y)+\langle T y, \eta(y, x)\rangle+\frac{1}{r}\langle y-x, x-z\rangle \\
& \quad \geq \Phi(x, y)+\langle T x, \eta(y, x)\rangle+\alpha(y-x)+\frac{1}{r}\langle y-x, x-z\rangle \\
& \quad \geq \alpha(y-x) .
\end{aligned}
$$


It follows that $x \in G_{z}(y)$ and so

$$
F_{z}(y) \subset G_{z}(y), \quad \forall y \in C
$$

This implies that $G_{z}$ is also a KKM mapping. Now, since $x \mapsto\langle T y, \eta(x, y)\rangle$ is a convex lowersemicontinuous function, we know that it is weakly lower semicontinuous. Thus from the definition of $G_{z}$ and the weak lower semicontinuity of $\alpha$, it follows that $G_{z}(y)$ is weakly closed for all $y \in C$. Since $C$ is bounded closed and convex, we know that $C$ is weakly compact, and so $G_{z}(y)$ is weakly compact in $C$ for each $y \in C$. It follows from Lemmas 2.2 and 2.4 that

$$
\bigcap_{y \in C} F_{z}(y)=\bigcap_{y \in C} G_{z}(y) \neq \emptyset
$$

Hence there exists $x \in C$ such that

$$
\Phi(x, y)+\langle T x, \eta(y, x)\rangle+\frac{1}{r}\langle y-x, x-z\rangle \geq 0, \quad \forall y \in C .
$$

This completes the proof.

Lemma 2.6. Let $H$ be a real Hilbert space and let $C$ be a nonempty bounded closed convex subset of $H$. Let $T: C \rightarrow H$ be an $\eta$-hemicontinuous and relaxed $\eta$ - $\alpha$ monotone mapping and let $\Phi$ be a bifunction from $C \times C$ to $\mathbb{R}$ satisfying (A1), (A2), and (A4). Let $r>0$ and define a mapping $T_{r}: H \rightarrow C$ as follows:

$$
T_{r}(x)=\left\{z \in C: \Phi(z, y)+\langle T z, \eta(y, z)\rangle+\frac{1}{r}\langle y-z, z-x\rangle \geq 0, \forall y \in C\right\}
$$

for all $x \in H$. Assume that

(i) $\eta(x, y)+\eta(y, x)=0$, for all $x, y \in C$;

(ii) for any fixed $u, v \in C$, the mapping $x \mapsto\langle T v, \eta(x, u)\rangle$ is convex and lower semicontinuous and the mapping $x \mapsto\langle T u, \eta(v, x)\rangle$ is lower semicontinuous;

(iii) $\alpha: H \rightarrow \mathbb{R}$ is weakly lower semicontinuous;

(iv) for any $x, y \in C, \alpha(x-y)+\alpha(y-x) \geq 0$.

Then, the following holds:

(1) $T_{r}$ is single-valued;

(2) $T_{r}$ is a firmly nonexpansive mapping, that is, for all $x, y \in H$,

$$
\left\|T_{r} x-T_{r} y\right\|^{2} \leq\left\langle T_{r} x-T_{r} y, x-y\right\rangle
$$

(3) $F\left(T_{r}\right)=E P(\Phi, T)$;

(4) $\operatorname{EP}(\Phi, T)$ is closed and convex. 
Proof. The fact that $T_{r}$ is nonempty is exactly the thesis of the previous lemma. We claim that $T_{r}$ is single-valued. Indeed, for $x \in H$ and $r>0$, let $z_{1}, z_{2} \in T_{r} x$. Then,

$$
\begin{aligned}
& \Phi\left(z_{1}, z_{2}\right)+\left\langle T z_{1}, \eta\left(z_{2}, z_{1}\right)\right\rangle+\frac{1}{r}\left\langle z_{2}-z_{1}, z_{1}-x\right\rangle \geq 0 \\
& \Phi\left(z_{2}, z_{1}\right)+\left\langle T z_{2}, \eta\left(z_{1}, z_{2}\right)\right\rangle+\frac{1}{r}\left\langle z_{1}-z_{2}, z_{2}-x\right\rangle \geq 0 .
\end{aligned}
$$

Adding the two inequalities, from (i) we have

$$
\Phi\left(z_{1}, z_{2}\right)+\Phi\left(z_{2}, z_{1}\right)+\left\langle T z_{1}-T z_{2}, \eta\left(z_{2}, z_{1}\right)\right\rangle+\frac{1}{r}\left\langle z_{1}-z_{2}, z_{2}-z_{1}\right\rangle \geq 0
$$

From (A2), we have

$$
\left\langle T z_{1}-T z_{2}, \eta\left(z_{2}, z_{1}\right)\right\rangle+\frac{1}{r}\left\langle z_{1}-z_{2}, z_{2}-z_{1}\right\rangle \geq 0
$$

that is,

$$
\frac{1}{r}\left\langle z_{1}-z_{2}, z_{2}-z_{1}\right\rangle \geq\left\langle T z_{2}-T z_{1}, \eta\left(z_{2}, z_{1}\right)\right\rangle
$$

Since $T$ is relaxed $\eta-\alpha$ monotone and $r>0$, one has

$$
\left\langle z_{1}-z_{2}, z_{2}-z_{1}\right\rangle \geq \operatorname{r\alpha }\left(z_{2}-z_{1}\right)
$$

In (2.29) exchanging the position of $z_{1}$ and $z_{2}$, we get

$$
\frac{1}{r}\left\langle z_{2}-z_{1}, z_{1}-z_{2}\right\rangle \geq\left\langle T z_{1}-T z_{2}, \eta\left(z_{1}, z_{2}\right)\right\rangle \geq \alpha\left(z_{1}-z_{2}\right),
$$

that is,

$$
\left\langle z_{1}-z_{2}, z_{2}-z_{1}\right\rangle \geq r \alpha\left(z_{1}-z_{2}\right)
$$

Now, adding the inequalities (2.30) and (2.32), by using (iv) we have

$$
-2\left\|z_{1}-z_{2}\right\|^{2}=2\left\langle z_{1}-z_{2}, z_{2}-z_{1}\right\rangle \geq 0
$$

Hence, $z_{1}=z_{2}$. 
Next we show that $T_{r}$ is firmly nonexpansive. Indeed, for $x, y \in H$, we have

$$
\begin{aligned}
& \Phi\left(T_{r} x, T_{r} y\right)+\left\langle T T_{r} x, \eta\left(T_{r} y, T_{r} x\right)\right\rangle+\frac{1}{r}\left\langle T_{r} y-T_{r} x, T_{r} x-x\right\rangle \geq 0, \\
& \Phi\left(T_{r} y, T_{r} x\right)+\left\langle T T_{r} y, \eta\left(T_{r} x, T_{r} y\right)\right\rangle+\frac{1}{r}\left\langle T_{r} x-T_{r} y, T_{r} y-y\right\rangle \geq 0 .
\end{aligned}
$$

Adding the two inequalities and by (i) and (A2), we get

$$
\left\langle T T_{r} x-T T_{r} y, \eta\left(T_{r} y, T_{r} x\right)\right\rangle+\frac{1}{r}\left\langle T_{r} y-T_{r} x, T_{r} x-T_{r} y-x+y\right\rangle \geq 0
$$

that is,

$$
\begin{aligned}
\frac{1}{r}\left\langle T_{r} y-T_{r} x, T_{r} x-T_{r} y-x+y\right\rangle & \geq\left\langle T T_{r} y-T T_{r} x, \eta\left(T_{r} y, T_{r} x\right)\right\rangle \\
& \geq \alpha\left(T_{r} y-T_{r} x\right) .
\end{aligned}
$$

In (2.36) exchanging the position of $T_{r} x$ and $T_{r} y$, we get

$$
\frac{1}{r}\left\langle T_{r} x-T_{r} y, T_{r} y-T_{r} x-y+x\right\rangle \geq \alpha\left(T_{r} x-T_{r} y\right) .
$$

Adding the inequalities (2.36) and (2.37), we have

$$
2\left\langle T_{r} x-T_{r} y, T_{r} y-T_{r} x-y+x\right\rangle \geq r\left(\alpha\left(T_{r} x-T_{r} y\right)+\alpha\left(T_{r} y-T_{r} x\right)\right) .
$$

It follows from (iv) that

$$
\left\langle T_{r} x-T_{r} y, T_{r} y-T_{r} x-y+x\right\rangle \geq 0,
$$

that is,

$$
\left\|T_{r} x-T_{r} y\right\|^{2} \leq\left\langle T_{r} x-T_{r} y, x-y\right\rangle .
$$

This shows that $T_{r}$ is firmly nonexpansive. 
Fixed Point Theory and Applications

Next, we claim that $F\left(T_{r}\right)=\mathrm{EP}(\Phi, T)$. Indeed, we have the following:

$$
\begin{aligned}
u \in F\left(T_{r}\right) & \Longleftrightarrow u=T_{r} u \\
& \Longleftrightarrow \Phi(u, y)+\langle T u, \eta(y, u)\rangle+\frac{1}{r}\langle y-u, u-u\rangle \geq 0, \quad \forall y \in C \\
& \Longleftrightarrow \Phi(u, y)+\langle T u, \eta(y, u)\rangle \geq 0, \quad \forall y \in C \\
& \Longleftrightarrow u \in \operatorname{EP}(\Phi, T) .
\end{aligned}
$$

Finally, we prove that $\operatorname{EP}(\Phi, T)$ is closed and convex. Indeed, Since every firm nonexpansive mapping is nonexpansive, we see that $T_{r}$ is nonexpansive from (2). On the other hand, since the set of fixed points of every nonexpansive mapping is closed and convex, we have that $\operatorname{EP}(\Phi, T)$ is closed and convex from (2) and (3). This completes the proof.

\section{Main Results}

In this section, we prove a strong convergence theorem which is our main result.

Theorem 3.1. Let $C$ be a nonempty bounded closed convex subset of a real Hilbert space $H$ and let $\Phi: C \times C \rightarrow \mathbb{R}$ be a bifunction satisfying (A1), (A2), (A3), and (A4). Let $T: C \rightarrow H$ be an $\eta$-hemicontinuous and relaxed $\eta$ - $\alpha$ monotone mapping, let $A: C \rightarrow H$ be a $\lambda$-inverse-strongly monotone mapping, and let $\left\{S_{n}\right\}_{n=1}^{\infty}: C \rightarrow C$ be a countable family of nonexpansive mappings such that $F=\bigcap_{n=1}^{\infty} \operatorname{Fix}\left(S_{n}\right) \cap \operatorname{GEP}(\Phi, T) \neq \emptyset$. Assume that the conditions (i)-(iv) of Lemma 2.6 are satisfied. Let $\alpha_{0}=1$ and assume that $\left\{\alpha_{n}\right\}_{n=1}^{\infty} \subset(0,1)$ is a strictly decreasing sequence. Assume that $\left\{\beta_{n}\right\}_{n=1}^{\infty} \subset(c, d)$ with some $c, d \in(0,1)$ and $\left\{\lambda_{n}\right\}_{n=1}^{\infty} \subset[a, b]$ with some $a, b \in(0,2 \lambda)$. Then, for any $x_{1} \in C$, the sequence $\left\{x_{n}\right\}$ generated by (1.14) converges strongly to $x^{*}=P_{F} x_{1}$. In particular, if $C$ contains the origin 0 , taking $x_{1}=0$, then the sequence $\left\{x_{n}\right\}$ generated by (1.14) converges strongly to the minimum norm element in $F$.

Proof. We split the proof into following steps.

Step 1. F is closed and convex, the sequence $\left\{x_{n}\right\}$ generated by (1.14) is well defined, and $F \subset D_{n}$ for all $n \geq 1$.

First, we prove that $F$ is closed and convex. It suffices to prove that $\operatorname{GEP}(\Phi, T)$ is closed and convex. Indeed, it is easy to prove the conclusion by the following fact:

$$
\begin{aligned}
\forall p \in \operatorname{GEP}(\Phi, T) & \Longleftrightarrow \Phi(p, y)+\langle T p, \eta(y, p)\rangle+\frac{1}{\lambda_{n}}\left\langle y-p, \lambda_{n} A p\right\rangle \geq 0, \quad \forall y \in C \\
& \Longleftrightarrow \Phi(p, y)+\langle T p, \eta(y, p)\rangle+\frac{1}{\lambda_{n}}\left\langle y-p, p-\left(p-\lambda_{n} A p\right)\right\rangle \geq 0, \quad \forall y \in C \\
& \Longleftrightarrow p=T_{\lambda_{n}}\left(I-\lambda_{n} A\right) p .
\end{aligned}
$$


This implies that $\operatorname{GEP}(\Phi, T)=\operatorname{Fix}\left[T_{\lambda_{n}}\left(I-\lambda_{n} A\right)\right]$. Noting that $T_{\lambda_{n}}\left(I-\lambda_{n} A\right)$ is a nonexpansive mapping for $\lambda_{n}<2 \lambda$ and the set of fixed points of a nonexpansive mapping is closed and convex, we have that $\operatorname{GEP}(\Phi, T)$ is closed and convex.

Next we prove that the sequence $\left\{x_{n}\right\}$ generated by (1.14) is well defined and $F \subset D_{n}$ for all $n \geq 1$. It is easy to see that $C_{n}$ is closed and convex for all $n \in \mathbb{N}$ from the construction of $C_{n}$. Hence, $D_{n}$ is closed and convex for all $n \in \mathbb{N}$. For any $p \in F$, since $u_{n}=T_{\lambda_{n}}\left(x_{n}-\lambda_{n} A x_{n}\right)$ and $I-\lambda_{n} A$ is nonexpansive, we have (note that $\left\{\alpha_{n}\right\}$ is strictly decreasing)

$$
\begin{aligned}
\left\|y_{n}-p\right\|= & \left\|\alpha_{n}\left(x_{n}-p\right)+\sum_{i=1}^{n}\left(\alpha_{i-1}-\alpha_{i}\right) \beta_{n}\left(S_{i} x_{n}-p\right)+\left(1-\alpha_{n}\right)\left(1-\beta_{n}\right)\left(u_{n}-p\right)\right\| \\
\leq & \alpha_{n}\left\|x_{n}-p\right\|+\sum_{i=1}^{n}\left(\alpha_{i-1}-\alpha_{i}\right) \beta_{n}\left\|S_{i} x_{n}-p\right\|+\left(1-\alpha_{n}\right)\left(1-\beta_{n}\right)\left\|u_{n}-p\right\| \\
\leq & \alpha_{n}\left\|x_{n}-p\right\|+\sum_{i=1}^{n}\left(\alpha_{i-1}-\alpha_{i}\right) \beta_{n}\left\|x_{n}-p\right\| \\
& +\left(1-\alpha_{n}\right)\left(1-\beta_{n}\right)\left\|T_{\lambda_{n}}\left(x_{n}-\lambda_{n} A x_{n}\right)-T_{\lambda_{n}}\left(p-\lambda_{n} A p\right)\right\| \\
\leq & \alpha_{n}\left\|x_{n}-p\right\|+\left(1-\alpha_{n}\right) \beta_{n}\left\|x_{n}-p\right\| \\
& +\left(1-\alpha_{n}\right)\left(1-\beta_{n}\right)\left\|\left(x_{n}-\lambda_{n} A x_{n}\right)-\left(p-\lambda_{n} A p\right)\right\| \\
\leq & \alpha_{n}\left\|x_{n}-p\right\|+\left(1-\alpha_{n}\right) \beta_{n}\left\|x_{n}-p\right\|+\left(1-\alpha_{n}\right)\left(1-\beta_{n}\right)\left\|x_{n}-p\right\| \\
= & \left\|x_{n}-p\right\| .
\end{aligned}
$$

So, $F \subset C_{n}$ for all $n \in \mathbb{N}$. Hence $F \subset \bigcap_{j=1}^{n} C_{j}$, that is, $F \subset D_{n}$ for all $n \in \mathbb{N}$. Since $D_{n}$ is closed, convex, and nonempty, the sequence $\left\{x_{n}\right\}$ is well defined.

Step 2. $\lim _{n \rightarrow \infty}\left\|x_{n+1}-x_{n}\right\|=0$ and there exists $x^{*} \in C$ such that $x_{n} \rightarrow x^{*}$ as $n \rightarrow \infty$.

From the definition of $D_{n}$, we see that $D_{n+1} \subset D_{n}$ for all $n \in \mathbb{N}$ and hence

$$
x_{n+2}=P_{D_{n+1}} x_{1} \in D_{n+1} \subset D_{n} .
$$

Noting that $x_{n+1}=P_{D_{n}} x_{1}$, we get

$$
\left\|x_{n+1}-x_{1}\right\| \leq\left\|x_{n+2}-x_{1}\right\|
$$

for all $n \geq 1$. This shows that $\left\{\left\|x_{n}-x_{1}\right\|\right\}$ is increasing. Since $C$ is bounded, $\left\{\left\|x_{n}-x_{1}\right\|\right\}$ is bounded. So, we have that $\lim _{n \rightarrow \infty}\left\|x_{n}-x_{1}\right\|$ exists. 
Fixed Point Theory and Applications

Noting that $x_{n+1}=P_{D_{n}} x_{1}$ and $x_{m+1}=P_{D_{m}} x_{1} \in D_{m} \subset D_{n}$ for all $m \geq n$, we have

$$
\left\langle x_{n+1}-x_{1}, x_{m+1}-x_{n+1}\right\rangle \geq 0 .
$$

It follows from (3.5) that

$$
\begin{aligned}
\| x_{m+1} & -x_{n+1} \|^{2} \\
& =\left\|x_{m+1}-x_{1}-\left(x_{n+1}-x_{1}\right)\right\|^{2} \\
& =\left\|x_{m+1}-x_{1}\right\|^{2}+\left\|x_{n+1}-x_{1}\right\|^{2}-2\left\langle x_{m+1}-x_{1}, x_{n+1}-x_{1}\right\rangle \\
& =\left\|x_{m+1}-x_{1}\right\|^{2}+\left\|x_{n+1}-x_{1}\right\|^{2}-2\left\langle x_{n+1}-x_{1}, x_{m+1}-x_{n+1}+x_{n+1}-x_{1}\right\rangle \\
& =\left\|x_{m+1}-x_{1}\right\|^{2}-\left\|x_{n+1}-x_{1}\right\|^{2}-2\left\langle x_{n+1}-x_{1}, x_{m+1}-x_{n+1}\right\rangle \\
& \leq\left\|x_{m+1}-x_{1}\right\|^{2}-\left\|x_{n+1}-x_{1}\right\|^{2} .
\end{aligned}
$$

By taking $m=n+1$ in (3.6), we get

$$
\left\|x_{n+2}-x_{n+1}\right\| \leq\left\|x_{n+2}-x_{1}\right\|^{2}-\left\|x_{n+1}-x_{1}\right\|^{2}
$$

Since the limits of $\left\|x_{n}-x_{1}\right\|$ exists we get

$$
\lim _{n \rightarrow \infty}\left\|x_{n+2}-x_{n+1}\right\|=0,
$$

that is, $x_{n+1}-x_{n} \rightarrow 0$ as $n \rightarrow \infty$. Moreover, from (3.6) we also have

$$
\lim _{m, n \rightarrow \infty}\left\|x_{m+1}-x_{n+1}\right\|=0
$$

This shows that $\left\{x_{n}\right\}$ is a Cauchy sequence. Hence, there exists $x^{*} \in C$ such that

$$
x_{n} \longrightarrow x^{*} \in C, \quad \text { as } n \longrightarrow \infty .
$$

Step 3. $\lim _{n \rightarrow \infty}\left\|x_{n}-u_{n}\right\|=0$.

Since $x_{n+1} \in C_{n}$ and $x_{n}-x_{n+1} \rightarrow 0$ as $n \rightarrow \infty$, we have

$$
\left\|y_{n}-x_{n+1}\right\| \leq\left\|x_{n}-x_{n+1}\right\| \longrightarrow 0 \text { as } n \longrightarrow \infty,
$$

and hence

$$
\left\|y_{n}-x_{n}\right\| \leq\left\|y_{n}-x_{n+1}\right\|+\left\|x_{n}-x_{n+1}\right\| \longrightarrow 0 \quad \text { as } n \longrightarrow \infty
$$


Note that $u_{n}$ can be rewritten as $u_{n}=T_{\lambda_{n}}\left(x_{n}-\lambda_{n} A x_{n}\right)$ for all $n \geq 1$. Take $p \in F$. Since $p=T_{\lambda_{n}}\left(p-\lambda_{n} A p\right), A$ is $\lambda$-inverse-strongly monotone, and $0<\lambda_{n}<2 \lambda$, we know that, for all $n \in \mathbb{N}$,

$$
\begin{aligned}
\left\|u_{n}-p\right\|^{2} & =\left\|T_{\lambda_{n}}\left(x_{n}-\lambda_{n} A x_{n}\right)-T_{\lambda_{n}}\left(p-\lambda_{n} A p\right)\right\|^{2} \\
& \leq\left\|x_{n}-\lambda_{n} A x_{n}-p-\lambda_{n} A p\right\|^{2} \\
& =\left\|\left(x_{n}-p\right)-\lambda_{n}\left(A x_{n}-A p\right)\right\|^{2} \\
& =\left\|x_{n}-p\right\|^{2}-2 \lambda_{n}\left\langle x_{n}-p, A x_{n}-A p\right\rangle+\lambda_{n}^{2}\left\|A x_{n}-A p\right\|^{2} \\
& \leq\left\|x_{n}-p\right\|^{2}-2 \lambda_{n} \lambda\left\|A x_{n}-A p\right\|^{2}+\lambda_{n}^{2}\left\|A x_{n}-A p\right\|^{2} \\
& =\left\|x_{n}-p\right\|^{2}+\lambda_{n}\left(\lambda_{n}-2 \lambda\right)\left\|A x_{n}-A p\right\|^{2} \\
& \leq\left\|x_{n}-p\right\|^{2} .
\end{aligned}
$$

Using (1.14) and (3.13), we have (note that $\left\{\alpha_{n}\right\}$ is strictly decreasing)

$$
\begin{aligned}
\left\|y_{n}-p\right\|^{2}= & \left\|\alpha_{n}\left(x_{n}-p\right)+\sum_{i=1}^{n}\left(\alpha_{i-1}-\alpha_{i}\right) \beta_{n}\left(S_{i} x_{n}-p\right)+\left(1-\alpha_{n}\right)\left(1-\beta_{n}\right)\left(u_{n}-p\right)\right\|^{2} \\
\leq & \alpha_{n}\left\|x_{n}-p\right\|^{2}+\sum_{i=1}^{n}\left(\alpha_{i-1}-\alpha_{i}\right) \beta_{n}\left\|S_{i} x_{n}-p\right\|^{2}+\left(1-\alpha_{n}\right)\left(1-\beta_{n}\right)\left\|u_{n}-p\right\|^{2} \\
\leq & \alpha_{n}\left\|x_{n}-p\right\|^{2}+\sum_{i=1}^{n}\left(\alpha_{i-1}-\alpha_{i}\right) \beta_{n}\left\|x_{n}-p\right\|^{2} \\
& +\left(1-\alpha_{n}\right)\left(1-\beta_{n}\right)\left(\left\|x_{n}-p\right\|^{2}+\lambda_{n}\left(\lambda_{n}-2 \lambda\right)\left\|A x_{n}-A p\right\|^{2}\right) \\
= & \left\|x_{n}-p\right\|^{2}+\left(1-\alpha_{n}\right)\left(1-\beta_{n}\right) \lambda_{n}\left(\lambda_{n}-2 \lambda\right)\left\|A x_{n}-A p\right\|^{2},
\end{aligned}
$$

and hence

$$
\begin{aligned}
\left(1-\alpha_{n}\right)(1-d) a(2 \lambda-b)\left\|A x_{n}-A p\right\|^{2} & \leq\left(1-\alpha_{n}\right)\left(1-\beta_{n}\right) \lambda_{n}\left(2 \lambda-\lambda_{n}\right)\left\|A x_{n}-A p\right\|^{2} \\
& \leq\left\|x_{n}-p\right\|^{2}-\left\|y_{n}-p\right\|^{2} \\
& \leq\left\|x_{n}-y_{n}\right\|\left(\left\|x_{n}-p\right\|+\left\|y_{n}-p\right\|\right) .
\end{aligned}
$$

Since $\left\{x_{n}\right\}$ and $\left\{y_{n}\right\}$ are both bounded, $\alpha_{n} \rightarrow 0$, and $x_{n}-y_{n} \rightarrow 0$, we have

$$
A x_{n}-A p \longrightarrow 0 \text { as } n \longrightarrow \infty \text {. }
$$


Using Lemma 2.6, we get

$$
\begin{aligned}
\left\|u_{n}-p\right\|^{2}= & \left\|T_{\lambda_{n}}\left(x_{n}-\lambda_{n} A x_{n}\right)-T_{\lambda_{n}}\left(p-\lambda_{n} A p\right)\right\|^{2} \\
\leq & \left\langle x_{n}-\lambda_{n} A x_{n}-\left(p-\lambda_{n} A p\right), u_{n}-p\right\rangle \\
= & \frac{1}{2}\left(\left\|x_{n}-\lambda_{n} A x_{n}-\left(p-\lambda_{n} A p\right)\right\|^{2}+\left\|u_{n}-p\right\|^{2}\right. \\
& \left.\quad-\left\|x_{n}-\lambda_{n} A x_{n}-\left(p-\lambda_{n} A p\right)-\left(u_{n}-p\right)\right\|^{2}\right) \\
\leq & \frac{1}{2}\left(\left\|x_{n}-p\right\|^{2}+\left\|u_{n}-p\right\|^{2}-\left\|x_{n}-u_{n}-\lambda_{n}\left(A x_{n}-A p\right)\right\|^{2}\right) \\
= & \frac{1}{2}\left(\left\|x_{n}-p\right\|^{2}+\left\|u_{n}-p\right\|^{2}-\left\|x_{n}-u_{n}\right\|^{2}\right. \\
& \left.\quad+2 \lambda_{n}\left\langle x_{n}-u_{n}, A x_{n}-A p\right\rangle-\lambda_{n}^{2}\left\|A x_{n}-A p\right\|^{2}\right) .
\end{aligned}
$$

So, we have

$$
\left\|u_{n}-p\right\|^{2} \leq\left\|x_{n}-p\right\|^{2}-\left\|x_{n}-u_{n}\right\|^{2}+2 \lambda_{n}\left\langle x_{n}-u_{n}, A x_{n}-A p\right\rangle-\lambda_{n}^{2}\left\|A x_{n}-A p\right\|^{2} .
$$

From (3.18), we have

$$
\begin{aligned}
\| y_{n}- & p \|^{2} \\
= & \left\|\alpha_{n}\left(x_{n}-p\right)+\sum_{i=1}^{n}\left(\alpha_{i-1}-\alpha_{i}\right) \beta_{n}\left(S_{i} x_{n}-p\right)+\left(1-\alpha_{n}\right)\left(1-\beta_{n}\right)\left(u_{n}-p\right)\right\|^{2} \\
\leq & \alpha_{n}\left\|x_{n}-p\right\|^{2}+\sum_{i=1}^{n}\left(\alpha_{i-1}-\alpha_{i}\right) \beta_{n}\left\|x_{n}-p\right\|^{2}+\left(1-\alpha_{n}\right)\left(1-\beta_{n}\right)\left\|u_{n}-p\right\|^{2} \\
\leq & \alpha_{n}\left\|x_{n}-p\right\|^{2}+\left(1-\alpha_{n}\right) \beta_{n}\left\|x_{n}-p\right\|^{2}+\left(1-\alpha_{n}\right)\left(1-\beta_{n}\right) \\
& \times\left(\left\|x_{n}-p\right\|^{2}-\left\|x_{n}-u_{n}\right\|^{2}+2 \lambda_{n}\left\langle x_{n}-u_{n}, A x_{n}-A p\right\rangle-\lambda_{n}^{2}\left\|A x_{n}-A p\right\|^{2}\right) \\
\leq & \left\|x_{n}-p\right\|^{2}-\left(1-\alpha_{n}\right)\left(1-\beta_{n}\right)\left\|x_{n}-u_{n}\right\|^{2}+2\left(1-\alpha_{n}\right)\left(1-\beta_{n}\right) \lambda_{n}\left\langle x_{n}-u_{n}, A x_{n}-A p\right\rangle,
\end{aligned}
$$

and hence

$$
\begin{aligned}
(1-d)\left(1-\alpha_{n}\right)\left\|x_{n}-u_{n}\right\|^{2} \leq & \left(1-\beta_{n}\right)\left(1-\alpha_{n}\right)\left\|x_{n}-u_{n}\right\|^{2} \\
\leq & \left\|x_{n}-y_{n}\right\|\left(\left\|x_{n}-p\right\|+\left\|y_{n}-p\right\|\right) \\
& +2\left(1-\alpha_{n}\right)\left(1-\beta_{n}\right) \lambda_{n}\left\|x_{n}-u_{n}\right\|\left\|A x_{n}-A p\right\| .
\end{aligned}
$$


By using $\left\|x_{n}-y_{n}\right\| \rightarrow 0$ and (3.16), we have

$$
\left\|x_{n}-u_{n}\right\| \longrightarrow 0 \text { as } n \longrightarrow \infty
$$

Step 4. $\lim _{n \rightarrow \infty}\left\|x_{n}-S_{i} x_{n}\right\|=0$, for all $i=0,1, \ldots$

It follows from the definition of scheme (1.14) that

$$
y_{n}+\sum_{i=1}^{n}\left(\alpha_{i-1}-\alpha_{i}\right) \beta_{n}\left(x_{n}-S_{i} x_{n}\right)-\left(1-\alpha_{n}\right) \beta_{n} x_{n}=\alpha_{n} x_{n}+\left(1-\alpha_{n}\right)\left(1-\beta_{n}\right) u_{n}
$$

that is,

$$
\begin{aligned}
\sum_{i=1}^{n}\left(\alpha_{i-1}-\alpha_{i}\right) \beta_{n}\left(x_{n}-S_{i} x_{n}\right) & =x_{n}-y_{n}-x_{n}+\alpha_{n} x_{n}+\left(1-\alpha_{n}\right) \beta_{n} x_{n}+\left(1-\alpha_{n}\right)\left(1-\beta_{n}\right) u_{n} \\
& =x_{n}-y_{n}+\left(1-\alpha_{n}\right)\left(\beta_{n}-1\right) x_{n}+\left(1-\alpha_{n}\right)\left(1-\beta_{n}\right) u_{n} \\
& =x_{n}-y_{n}+\left(1-\alpha_{n}\right)\left(1-\beta_{n}\right)\left(u_{n}-x_{n}\right) .
\end{aligned}
$$

Hence, for any $p \in F$, one has

$$
\sum_{i=1}^{n}\left(\alpha_{i-1}-\alpha_{i}\right) \beta_{n}\left\langle x_{n}-S_{i} x_{n}, x_{n}-p\right\rangle=\left(1-\alpha_{n}\right)\left(1-\beta_{n}\right)\left\langle u_{n}-x_{n}, x_{n}-p\right\rangle+\left\langle x_{n}-y_{n}, x_{n}-p\right\rangle .
$$

Since each $S_{i}$ is nonexpansive, by (2.4) we have

$$
\left\|S_{i} x_{n}-x_{n}\right\|^{2} \leq 2\left\langle x_{n}-S_{i} x_{n}, x_{n}-p\right\rangle .
$$

Hence, combining this inequality with (3.24), we get

$$
\frac{1}{2} \sum_{i=1}^{n}\left(\alpha_{i-1}-\alpha_{i}\right) \beta_{n}\left\|S_{i} x_{n}-x_{n}\right\|^{2} \leq\left(1-\alpha_{n}\right)\left(1-\beta_{n}\right)\left\langle u_{n}-x_{n}, x_{n}-p\right\rangle+\left\langle x_{n}-y_{n}, x_{n}-p\right\rangle,
$$

that is (noting that $\left\{\alpha_{n}\right\}$ is strictly decreasing),

$$
\begin{aligned}
\left\|S_{i} x_{n}-x_{n}\right\|^{2} & \leq \frac{2\left(1-\alpha_{n}\right)\left(1-\beta_{n}\right)}{\left(\alpha_{i-1}-\alpha_{i}\right) \beta_{n}}\left\langle u_{n}-x_{n}, x_{n}-p\right\rangle+\frac{2}{\left(\alpha_{i-1}-\alpha_{i}\right) \beta_{n}}\left\langle x_{n}-y_{n}, x_{n}-p\right\rangle \\
& \leq \frac{2\left(1-\alpha_{n}\right)\left(1-\beta_{n}\right)}{\left(\alpha_{i-1}-\alpha_{i}\right) \beta_{n}}\left\|u_{n}-x_{n}\right\|\left\|x_{n}-p\right\|+\frac{2}{\left(\alpha_{i-1}-\alpha_{i}\right) \beta_{n}}\left\|x_{n}-y_{n}\right\|\left\|x_{n}-p\right\| .
\end{aligned}
$$

Since $\left\|u_{n}-x_{n}\right\| \rightarrow 0$ and $\left\|x_{n}-y_{n}\right\| \rightarrow 0$, we have

$$
\lim _{n \rightarrow \infty}\left\|S_{i} x_{n}-x_{n}\right\|=0, \quad \forall i=1,2, \ldots
$$


Step 5. $x_{n} \rightarrow x^{*}=P_{F} x_{1}$.

First we prove $x^{*} \in \bigcap_{i=1}^{\infty} \operatorname{Fix}\left(S_{i}\right)$. Indeed, since $x_{n} \rightarrow x^{*}$ and $S_{i} x_{n}-x_{n} \rightarrow 0$, we have $x^{*} \in \operatorname{Fix}\left(S_{i}\right)$ for each $i=1,2, \ldots$. Hence, $x^{*} \in \bigcap_{i=1}^{\infty} \operatorname{Fix}\left(S_{i}\right)$.

Next, we show that $x^{*} \in \operatorname{GEP}(\Phi, T)$. Noting that $u_{n}=T_{\lambda_{n}}\left(x_{n}-\lambda_{n} A x_{n}\right)$, one obtains

$$
\Phi\left(u_{n}, y\right)+\left\langle T u_{n}, \eta\left(y, u_{n}\right)\right\rangle+\left\langle A x_{n}, y-u_{n}\right\rangle+\frac{1}{\lambda_{n}}\left\langle y-u_{n}, u_{n}-x_{n}\right\rangle \geq 0, \quad \forall y \in C
$$

Put $u_{t}=t y+(1-t) x^{*}$ for all $t \in(0,1)$ and $y \in C$. Then, we have $u_{t} \in C$. So, from (A2), (i), and (3.29) we have

$$
\begin{aligned}
\left\langle u_{t}-u_{n}, A u_{t}\right\rangle \geq & \left\langle u_{t}-u_{n}, A u_{t}\right\rangle-\left\langle u_{t}-u_{n}, A x_{n}\right\rangle-\left\langle u_{t}-u_{n}, \frac{u_{n}-x_{n}}{\lambda_{n}}\right\rangle \\
& +\Phi\left(u_{t}, u_{n}\right)+\left\langle T u_{n}, \eta\left(u_{n}, u_{t}\right)\right\rangle \\
= & \left\langle u_{t}-u_{n}, A u_{t}-A u_{n}\right\rangle+\left\langle u_{t}-u_{n}, A u_{n}-A x_{n}\right\rangle-\left\langle u_{t}-u_{n}, \frac{u_{n}-x_{n}}{\lambda_{n}}\right\rangle \\
& +\Phi\left(u_{t}, u_{n}\right)+\left\langle T u_{n}, \eta\left(u_{n}, u_{t}\right)\right\rangle .
\end{aligned}
$$

Since $x_{n}-u_{n} \rightarrow 0$, we have $\left\|A u_{n}-A x_{n}\right\| \rightarrow 0$. Further, from monotonicity of $A$, we have $\left\langle u_{t}-u_{n}, A u_{t}-A u_{n}\right\rangle \geq 0$. So, from (A4), (ii), and $\eta$-hemicontinuity of $T$ we have

$$
\left\langle u_{t}-x^{*}, A u_{t}\right\rangle \geq \Phi\left(u_{t}, x^{*}\right)+\left\langle T x^{*}, \eta\left(x^{*}, u_{t}\right)\right\rangle \text {. }
$$

From (A1), (A4), (ii), and (3.31) we also have

$$
\begin{aligned}
0= & \Phi\left(u_{t}, u_{t}\right)+\left\langle T x^{*}, \eta\left(u_{t}, u_{t}\right)\right\rangle \\
\leq & t\left[\Phi\left(u_{t}, y\right)+\left\langle T x^{*}, \eta\left(y, u_{t}\right)\right\rangle\right] \\
& +(1-t)\left[\Phi\left(u_{t}, x^{*}\right)+\left\langle T x^{*}, \eta\left(x^{*}, u_{t}\right)\right\rangle\right] \\
\leq & t\left[\Phi\left(u_{t}, y\right)+\left\langle T x^{*}, \eta\left(y, u_{t}\right)\right\rangle\right]+(1-t)\left\langle u_{t}-x^{*}, A u_{t}\right\rangle \\
= & t\left[\Phi\left(u_{t}, y\right)+\left\langle T x^{*}, \eta\left(y, u_{t}\right)\right]+(1-t) t\left\langle y-x^{*}, A u_{t}\right\rangle,\right.
\end{aligned}
$$

and hence

$$
0 \leq \Phi\left(u_{t}, y\right)+\left\langle T x^{*}, \eta\left(y, u_{t}\right)+(1-t)\left\langle y-x^{*}, A u_{t}\right\rangle\right.
$$

Letting $t \rightarrow 0$, from (A3) and (ii) we have, for each $y \in C$,

$$
0 \leq \Phi\left(x^{*}, y\right)+\left\langle T x^{*}, \eta\left(y, x^{*}\right)+\left\langle y-x^{*}, A x^{*}\right\rangle\right.
$$

This implies that $x^{*} \in \operatorname{GEP}(\Phi, T)$. Hence, we get $x^{*} \in F=\bigcap_{n=1}^{\infty} \operatorname{Fix}\left(S_{n}\right) \cap \operatorname{GEP}(\Phi, T)$. 
Finally, we show that $x^{*}=P_{F} x$. Indeed, from $x_{n+1}=P_{D_{n}} x$ and $F \subset D_{n}$, we have

$$
\left\langle x-x_{n+1}, x_{n+1}-v\right\rangle \geq 0, \quad \forall v \in F .
$$

Taking the limit in (3.35) and noting that $x_{n} \rightarrow x^{*}$ as $n \rightarrow \infty$, we get

$$
\left\langle x-x^{*}, x^{*}-v\right\rangle \geq 0, \quad \forall v \in F
$$

In view of (2.3), one sees that $x^{*}=P_{F} x$. This completes the proof.

Corollary 3.2. Let $C$ be a nonempty bounded closed convex subset of a Hilbert space $H$ and let $\Phi: C \times C \rightarrow \mathbb{R}$ be a bifunction satisfying (A1), (A2), (A3), and (A4). Let $T: C \rightarrow H$ be an $\eta$ hemicontinuous and relaxed $\eta$ - $\alpha$ monotone mapping and let $S: C \rightarrow C$ be a nonexpansive mapping such that $\operatorname{Fix}(S) \cap \operatorname{EP}(\Phi, T) \neq \emptyset$. Assume that the conditions (i)-(iv) of Lemma 2.6 are satisfied. Assume that $\left\{\alpha_{n}\right\}_{n=1}^{\infty} \subset(0,1)$ with $\limsup _{n \rightarrow \infty} \alpha_{n}<1,\left\{\beta_{n}\right\}_{n=1}^{\infty} \subset(c, d)$ with some $c, d \in(0,1)$ and $\left\{\lambda_{n}\right\}_{n=1}^{\infty} \subset(a, \infty)$ with $a \in(0, \infty)$. Let $x_{1} \in C$ and let $\left\{x_{n}\right\}$ be generated by

$$
\begin{gathered}
\Phi\left(u_{n}, y\right)+\left\langle T u_{n}, \eta\left(y, u_{n}\right)\right\rangle+\frac{1}{\lambda_{n}}\left\langle y-u_{n}, u_{n}-x_{n}\right\rangle \geq 0, \quad \forall y \in C, \\
y_{n}=\alpha_{n} x_{n}+\left(1-\alpha_{n}\right) \beta_{n} S x_{n}+\left(1-\alpha_{n}\right)\left(1-\beta_{n}\right) u_{n}, \\
C_{n}=\left\{z \in C:\left\|y_{n}-z\right\| \leq\left\|x_{n}-z\right\|\right\}, \\
D_{n}=\bigcap_{j=1}^{n} C_{j}, \\
x_{n+1}=P_{D_{n}} x_{1}, \quad n \geq 1 .
\end{gathered}
$$

Then the sequence $\left\{x_{n}\right\}$ converges strongly to $x^{*}=P_{\operatorname{Fix}(S) \cap E P(\Phi, T)} x_{1}$. In particular, if $C$ contains the origin 0 , taking $x_{1}=0$, the sequence $\left\{x_{n}\right\}$ converges strongly to the minimum norm element in $\operatorname{Fix}(S) \cap E P(\Phi, T)$.

Proof. In Theorem 3.1, put $A \equiv 0, S_{1}=\cdots=S_{n}=\cdots=S$. Then, we have

$$
\begin{aligned}
y_{n} & =\alpha_{n} x_{n}+\sum_{i=1}^{n}\left(\alpha_{i-1}-\alpha_{i}\right) \beta_{n} S_{i} x_{n}+\left(1-\alpha_{n}\right)\left(1-\beta_{n}\right) u_{n} \\
& =\alpha_{n} x_{n}+\left(1-\alpha_{n}\right) \beta_{n} S x_{n}+\left(1-\alpha_{n}\right)\left(1-\beta_{n}\right) u_{n}, \\
\left\|S x_{n}-x_{n}\right\|^{2} & \leq \frac{2\left(1-\alpha_{n}\right)\left(1-\beta_{n}\right)}{\left(1-\alpha_{n}\right) \beta_{n}}\left\|u_{n}-x_{n}\right\|\left\|x_{n}-p\right\|+\frac{2}{\left(1-\alpha_{n}\right) \beta_{n}}\left\|x_{n}-y_{n}\right\|\left\|x_{n}-p\right\| .
\end{aligned}
$$

On the other hand, for all $\lambda \in(0, \infty)$, we have that

$$
\langle x-y, A x-A y\rangle \geq \lambda\|A x-A y\|^{2}, \quad \forall x, y \in C .
$$


So, taking $a, b \in(0, \infty)$ with $0<a \leq b<\infty$ and choosing a sequence $\left\{\lambda_{n}\right\}$ of real numbers with $a \leq \lambda_{n} \leq b$, we obtain the desired result by Theorem 3.1.

Corollary 3.3. Let $C$ be a nonempty bounded closed convex subset of a Hilbert space $H$ and let $\Phi: C \times C \rightarrow \mathbb{R}$ be a bifunction satisfying (A1), (A2), (A3), and (A4). Let $T: C \rightarrow H$ be a monotone mapping and let $S: C \rightarrow C$ be a nonexpansive mapping such that $\operatorname{Fix}(S) \cap E P(\Phi, T) \neq \emptyset$. Assume that $\left\{\alpha_{n}\right\}_{n=1}^{\infty} \subset(0,1)$ with $\lim \sup _{n \rightarrow \infty} \alpha_{n}<1,\left\{\beta_{n}\right\}_{n=1}^{\infty} \subset(c, d)$ with some $c, d \in(0,1)$ and $\left\{\lambda_{n}\right\}_{n=1}^{\infty} \subset(a, \infty)$ with $a \in(0, \infty)$. Let $x_{1} \in C$ and let $\left\{x_{n}\right\}$ be generated by

$$
\begin{gathered}
\Phi\left(u_{n}, y\right)+\left\langle T u_{n}, y-u_{n}\right\rangle+\frac{1}{\lambda_{n}}\left\langle y-u_{n}, u_{n}-x_{n}\right\rangle \geq 0, \quad \forall y \in C, \\
y_{n}=\alpha_{n} x_{n}+\left(1-\alpha_{n}\right) \beta_{n} S x_{n}+\left(1-\alpha_{n}\right)\left(1-\beta_{n}\right) u_{n}, \\
C_{n}=\left\{z \in C:\left\|y_{n}-z\right\| \leq\left\|x_{n}-z\right\|\right\}, \\
D_{n}=\bigcap_{j=1}^{n} C_{j}, \\
x_{n+1}=P_{D_{n}} x, \quad n \geq 1 .
\end{gathered}
$$

Then the sequence $\left\{x_{n}\right\}$ converges strongly to $x^{*}=P_{\mathrm{Fix}(S) \cap E P(\Phi, T)} x_{1}$. In particular, if $C$ contains the origin 0 , taking $x_{1}=0$, the sequence $\left\{x_{n}\right\}$ converges strongly to the minimum norm element in $\operatorname{Fix}(S) \cap E P(\Phi, T)$.

Proof. In Corollary 3.2, put $\alpha \equiv 0$ and $\eta(x, y) \equiv x-y$ for all $x, y \in C$. Then $T: C \rightarrow H$ is a monotone mapping and we obtain the desired result by Theorem 3.1.

Corollary 3.4. Let $C$ be a closed convex subset of a Hilbert space $H$ and let $\Phi: C \times C \rightarrow \mathbb{R}$ be a bifunction satisfying (A1), (A2), (A3), and (A4). Let $A: C \rightarrow H$ be a $\lambda$-inverse-strongly monotone mapping and let $S: C \rightarrow C$ be a nonexpansive mapping such that $\operatorname{Fix}(S) \cap E P \neq \emptyset$. Assume that $\left\{\alpha_{n}\right\}_{n=1}^{\infty} \subset(0,1)$ with lim $\sup _{n \rightarrow \infty} \alpha_{n}<1,\left\{\beta_{n}\right\}_{n=1}^{\infty} \subset(c, d)$ with some $c, d \in(0,1)$ and $\left\{\lambda_{n}\right\}_{n=1}^{\infty} \subset(a, b)$ with $0<a, b<2 \lambda$. Let $x_{1} \in C$ and let $\left\{x_{n}\right\}$ be generated by

$$
\begin{gathered}
\Phi\left(u_{n}, y\right)+\left\langle A u_{n}, y-u_{n}\right\rangle+\frac{1}{\lambda_{n}}\left\langle y-u_{n}, u_{n}-x_{n}\right\rangle \geq 0, \quad \forall y \in C, \\
y_{n}=\alpha_{n} x_{n}+\left(1-\alpha_{n}\right) \beta_{n} S x_{n}+\left(1-\alpha_{n}\right)\left(1-\beta_{n}\right) u_{n}, \\
C_{n}=\left\{z \in C:\left\|y_{n}-z\right\| \leq\left\|x_{n}-z\right\|\right\}, \\
D_{n}=\bigcap_{j=1}^{n} C_{j}, \\
x_{n+1}=P_{D_{n}} x, \quad n \geq 1 .
\end{gathered}
$$

Then the sequence $\left\{x_{n}\right\}$ converges strongly to $x^{*}=P_{\mathrm{Fix}(S) \cap E P} x_{1}$. In particular, if $C$ contains the origin 0 , taking $x_{1}=0$, the sequence $\left\{x_{n}\right\}$ converges strongly to the minimum norm element in $\operatorname{Fix}(S) \cap E P$. 
Proof. In Theorem 3.1, put $T \equiv 0, \eta \equiv 0, \alpha \equiv 0$, and $S_{1}=\cdots=S_{n}=\cdots=S$. We obtain the desired result by Theorem 3.1.

Corollary 3.5. Let $C$ be a closed convex subset of a Hilbert space $H$ and let $\Phi: C \times C \rightarrow \mathbb{R}$ be a bifunction satisfying (A1), (A2), (A3), and (A4). Let $S: C \rightarrow C$ be a nonexpansive mapping such that $\operatorname{Fix}(S) \cap E P(\Phi) \neq \emptyset$. Assume that $\left\{\alpha_{n}\right\}_{n=1}^{\infty} \subset(0,1)$ with $\limsup _{n \rightarrow \infty} \alpha_{n}<1,\left\{\beta_{n}\right\}_{n=1}^{\infty} \subset(c, d)$ with some $c, d \in(0,1)$, and $\left\{\lambda_{n}\right\}_{n=1}^{\infty} \subset(a, \infty)$ with $0<a<\infty$. Let $x_{1} \in C$ and let $\left\{x_{n}\right\}$ be generated by

$$
\begin{gathered}
\Phi\left(u_{n}, y\right)+\frac{1}{\lambda_{n}}\left\langle y-u_{n}, u_{n}-x_{n}\right\rangle \geq 0, \quad \forall y \in C, \\
y_{n}=\alpha_{n} x_{n}+\left(1-\alpha_{n}\right) \beta_{n} S x_{n}+\left(1-\alpha_{n}\right)\left(1-\beta_{n}\right) u_{n}, \\
C_{n}=\left\{z \in C:\left\|y_{n}-z\right\| \leq\left\|x_{n}-z\right\|\right\}, \\
D_{n}=\bigcap_{j=1}^{n} C_{j}, \\
x_{n+1}=P_{D_{n}} x, \quad n \geq 1 .
\end{gathered}
$$

Then the sequence $\left\{x_{n}\right\}$ converges strongly to $x^{*}=P_{\mathrm{Fix}(S) \cap E P(\Phi)} x_{1}$. In particular, if $C$ contains the origin 0 , taking $x_{1}=0$, the sequence $\left\{x_{n}\right\}$ converges strongly to the minimum norm element in $\operatorname{Fix}(S) \cap E P(\Phi)$.

Proof. In Corollary 3.4, by putting $A \equiv 0$ we obtain the desired result.

Corollary 3.6. Let $C$ be a closed convex subset of a Hilbert space $H$ and let $A: C \rightarrow H$ be a $\lambda$ inverse-strongly monotone mapping. Let $S: C \rightarrow C$ be a nonexpansive mapping such that $\operatorname{Fix}(S) \cap$ $\operatorname{VI}(C, A) \neq \emptyset$. Assume that $\left\{\alpha_{n}\right\}_{n=1}^{\infty} \subset(0,1)$ with $\limsup _{n \rightarrow \infty} \alpha_{n}<1,\left\{\beta_{n}\right\}_{n=1}^{\infty} \subset(c, d)$ with some $c, d \in(0,1)$, and $\left\{\lambda_{n}\right\}_{n=1}^{\infty} \subset(a, b)$ with $0<a, b<2 \lambda$. Let $x_{1} \in C$ and let $\left\{x_{n}\right\}$ be generated by

$$
\begin{gathered}
u_{n}=P_{C}\left(x_{n}-\lambda_{n} A x_{n}\right), \\
y_{n}=\alpha_{n} x_{n}+\left(1-\alpha_{n}\right) \beta_{n} S x_{n}+\left(1-\alpha_{n}\right)\left(1-\beta_{n}\right) u_{n}, \\
C_{n}=\left\{z \in C:\left\|y_{n}-z\right\| \leq\left\|x_{n}-z\right\|\right\}, \\
D_{n}=\bigcap_{j=1}^{n} C_{j}, \\
x_{n+1}=P_{D_{n}} x, \quad n \geq 1 .
\end{gathered}
$$

Then the sequence $\left\{x_{n}\right\}$ converges strongly to $x^{*}=P_{\mathrm{Fix}(S) \cap V I(C, A)} x_{1}$. In particular, if $C$ contains the origin 0 , taking $x_{1}=0$, the sequence $\left\{x_{n}\right\}$ converges strongly to the minimum norm element in $\operatorname{Fix}(S) \cap V I(C, A)$. 
Proof. In Theorem 3.1, put $\Phi \equiv 0, T \equiv 0, \eta \equiv 0, \alpha \equiv 0$, and $S_{1}=\cdots=S_{n}=\cdots=S$. Then, we have

$$
u_{n}=P_{C}\left(x_{n}-\lambda_{n} A x_{n}\right), \quad \forall x \geq 1
$$

Then, we obtain the desired result by Theorem 3.1.

Remark 3.7. The novelty of this paper lies in the following aspects.

(i) A new general equilibrium problem with a relaxed monotone mapping is considered.

(ii) The definition of $D_{n}$ is of independent interest.

\section{Acknowledgment}

This work was supported by the Natural Science Foundation of Hebei Province (A2010001482).

\section{References}

[1] A. Tada and W. Takahashi, "Weak and strong convergence theorems for a nonexpansive mapping and an equilibrium problem," Journal of Optimization Theory and Applications, vol. 133, no. 3, pp. 359-370, 2007.

[2] S. Takahashi and W. Takahashi, "Viscosity approximation methods for equilibrium problems and fixed point problems in Hilbert spaces," Journal of Mathematical Analysis and Applications, vol. 331, no. 1, pp. 506-515, 2007.

[3] W. Takahashi, Nonlinear Functional Analysis, Fixed Point Theory and Its Applications, Yokohama Publishers, Yokohama, Japan, 2000.

[4] F. E. Browder and W. V. Petryshyn, "Construction of fixed points of nonlinear mappings in Hilbert space," Journal of Mathematical Analysis and Applications, vol. 20, pp. 197-228, 1967.

[5] W. Takahashi and M. Toyoda, "Weak convergence theorems for nonexpansive mappings and monotone mappings," Journal of Optimization Theory and Applications, vol. 118, no. 2, pp. 417-428, 2003.

[6] H. Iiduka and W. Takahashi, "Strong convergence theorems for nonexpansive mappings and inversestrongly monotone mappings," Nonlinear Analysis: Theory, Methods E Applications, vol. 61, no. 3, pp. 341-350, 2005.

[7] S. Plubtieng and R. Punpaeng, "A new iterative method for equilibrium problems and fixed point problems of nonexpansive mappings and monotone mappings," Applied Mathematics and Computation, vol. 197, no. 2, pp. 548-558, 2008.

[8] S. Wang, H. Zhou, and J. Song, "Viscosity approximation methods for equilibrium problems and fixed point problems of nonexpansive mappings and inverse-strongly monotone mappings," Methods and Applications of Analysis, vol. 14, no. 4, pp. 405-419, 2007.

[9] S. Takahashi and W. Takahashi, "Strong convergence theorem for a generalized equilibrium problem and a nonexpansive mapping in a Hilbert space," Nonlinear Analysis: Theory, Methods E Applications, vol. 69, no. 3, pp. 1025-1033, 2008.

[10] Y. P. Fang and N. J. Huang, "Variational-like inequalities with generalized monotone mappings in Banach spaces," Journal of Optimization Theory and Applications, vol. 118, no. 2, pp. 327-338, 2003.

[11] D. Goeleven and D. Motreanu, "Eigenvalue and dynamic problems for variational and hemivariational inequalities," Communications on Applied Nonlinear Analysis, vol. 3, no. 4, pp. 1-21, 1996.

[12] A. H. Siddiqi, Q. H. Ansari, and K. R. Kazmi, “On nonlinear variational inequalities,” Indian Journal of Pure and Applied Mathematics, vol. 25, no. 9, pp. 969-973, 1994. 
[13] R. U. Verma, “Nonlinear variational inequalities on convex subsets of Banach spaces," Applied Mathematics Letters, vol. 10, no. 4, pp. 25-27, 1997.

[14] K. K. Marzukiewicz, "Ein beweis des fixpuntsatzen fur n-dimensionale simplexe," Fundamenta Mathematicae, vol. 14, pp. 132-137, 1929. 